\title{
The Effect of Shear Mixing Speed and Time on the Mechanical Properties of GNP/Epoxy Composites
}

\author{
Edward Pullicino ${ }^{1}$ - Wentao Zou ${ }^{1} \cdot$ Matthieu Gresil $^{1}$ • \\ Costas Soutis ${ }^{1}$
}

Received: 29 September 2016 / Accepted: 31 October 2016/Published online: 8 December 2016

(C) The Author(s) 2016. This article is published with open access at Springerlink.com

\begin{abstract}
The aim of this study was to examine the effect of shear mixing speed and time on the mechanical properties of graphene nanoplatelet (GNP) composites. Shear mixing is cited in the literature as one method of making a good dispersion of nanofillers in a polymer that breaks down agglomerates into smaller particles and in the case of GNP can exfoliate layers of graphene. In this paper 0.1 to $5 \mathrm{wt} \%$ GNP was mixed with epoxy at different speeds and for different lengths of time. The composites were then cured and the tensile strength and Young's modulus was measured. Optical microscopy was performed to examine the dispersion of the GNP in the epoxy. The results show that the shear mixing speed and time affect the size of agglomerates, which has an impact on the mechanical properties of the composite. At $3000 \mathrm{rpm}$ and $2 \mathrm{~h}$ of mixing the average size of agglomerate was $26.3 \mu \mathrm{m}$ (30\% reduction compared to that of $1000 \mathrm{rpm}$ and $1 \mathrm{~h}$ duration), the tensile strength of epoxy was not affected by the addition of GNP, while a $12 \%$ increase was recorded for the Young's modulus. It is also found that functionalisation of the surface of the GNP improves the bond formed between the GNP and the resin that enhances its mechanical properties with no effect on the size of the agglomerates. Acetone was used to improve the GNP dispersion and found that shear mixing $5 \mathrm{wt} \%$ of GNP with acetone increases the Young's modulus up to 3.02 from 2.6 GPa for the neat epoxy, an almost $14 \%$ rise.
\end{abstract}

Keywords Nanotechnology·Graphene $\cdot$ Mechanical properties

\section{Introduction}

The quest has been underway to try and impart the properties of graphene to composite materials for some time. Appropriate dispersion of graphene within the polymer has been identified by the materials science community as one of the challenges to make graphene

Edward Pullicino

Edward.pullicino@postgrad.manchester.ac.uk

1 Aerospace Research Institute, University of Manchester, M13 9PL Manchester, UK 
nanocomposites with enhanced mechanical properties. Improper dispersion causes agglomeration of the graphene within the polymer leading to nanocomposites with reduced tensile strength and modulus where the GNP acts as a defect.

Research has shown that shear mixing as a technique is an effective and scalable way of dispersing GNP in epoxy. Shear mixing breaks agglomerates of GNPs apart and can exfoliate layers of graphene. Provided a good interface is formed between the graphene and the polymer this should lead to improved mechanical properties. According to ref. [1] the there exists a critical shear rate $\left(10^{4} \mathrm{~s}^{-1}\right)$ which is required to exfoliate graphene from GNPs regardless of the solvent used. In their experiment graphite particles were dispersed in a mixture of a solvent and a surfactant N-Methyl-2-pyrrolidone (NMP) and sodium cholate $(\mathrm{NaC})$ respectively. The initial concentration of graphite was $50 \mathrm{mg} \mathrm{ml}^{-1}$ in a volume of 4.51 . A Silverson L5M shear mixer was used at $4500 \mathrm{rpm}$ and for $20 \mathrm{~min}$. AFM, TEM and Raman Spectroscopy measurements showed that most of the graphite had been reduced to ten layers or less and that some mono layers of graphene had been produced.

They have also shown that some solvents are much better at exfoliating and stabilising graphene than others. Two parameters are used to measure the compatibility of graphene with the solvent. They are called the Hildenbrand Solubility parameter $\left(\delta_{\mathrm{T}}\right)$ and the Hansen solubility parameters $\left(\delta_{\mathrm{D}}, \delta_{\mathrm{P}}, \delta_{\mathrm{H}}\right) . \delta_{\mathrm{D}}$ is the equivalent of the energy from dispersion forces between molecules, $\delta_{\mathrm{P}}$ is the equivalent of energy from dipolar intermolecular forces between molecules and $\delta_{\mathrm{H}}$ is the equivalent of energy from hydrogen bonds between molecules. The parameters are linked by the equation:

$$
\delta_{T}=\sqrt{\delta_{D}^{2}+\delta_{P}^{2}+\delta_{H}^{2}}
$$

Good solvents for graphene should have a Hildebrand solubility parameter of $\delta_{\mathrm{T}} \sim 23 \mathrm{MPa}^{1 / 2}$ and Hansen Solubility parameters of $\delta_{\mathrm{D}} \sim 18 \mathrm{MPa}^{1 / 2}, \delta_{\mathrm{P}} \sim 9.3 \mathrm{MPa}^{1 / 2}$ and $\delta_{\mathrm{H}} \sim 7.7 \mathrm{MPa}^{1 / 2}$ [2]. Solvents which are near to these values help in the production rate because they stabilise the exfoliated flakes and prevent re-agglomeration. If there is a big mismatch in these parameters between the solvent and the ideal values the mixing will be not be as effective. Choosing a solvent is crucial therefore to the dispersion. Solvents like NMP are excellent for exfoliating graphene. It has a Hildenbrand parameter of $\delta_{\mathrm{T}}=23 \mathrm{MPa}^{1 / 2}$ and Hansen Solubility parameters of $\delta_{\mathrm{D}}=18 \mathrm{MPa}^{1 / 2}, \delta_{\mathrm{P}}=12.3 \mathrm{MPa}^{1 / 2}$ and $\delta_{\mathrm{H}}=7.2 \mathrm{MPa}^{1 / 2}$ which is very close to the ideal values. However, NMP has a high boiling point of $205^{\circ} \mathrm{C}$ which makes it difficult to remove from epoxy in the final composite because epoxy cures at much lower temperatures. Acetone is another solvent which can used $\left(\delta_{\mathrm{T}}=19.9 \mathrm{MPa}^{1 / 2}, \delta_{\mathrm{D}}=15.5 \mathrm{MPa}^{1 / 2}, \delta_{\mathrm{P}}=10.4 \mathrm{MPa}^{1 / 2}\right.$ and $\left.\delta_{\mathrm{H}}=7.0 \mathrm{MPa}^{1 / 2}\right)$. Although it is not as good as NMP for dispersion it has lower boiling point of $56^{\circ} \mathrm{C}$ so it is much easier to remove from the final composite. Even poor solvents such as acetone were capable of producing $63 \%$ of flakes with 1-5 layers [1].

To the knowledge of the authors no work has been performed on the effect of mixing speed and time on GNP directly into epoxy without solvent. The use of solvents in epoxy could negatively affect the mechanical and electrical properties of the composite. The solvent must be removed from the final composite before curing which can be difficult. This forms the reason for carrying out this investigation. Any process which does not require a solvent would be less expensive and easier. In addition, since relatively low cost solvents such as acetone are capable of producing $63 \%$ of flakes with 1-5 layers it maybe be that given sufficient mixing time similar results can be achieved mixing in epoxy resin as long as the shear rate exceeds $10^{4} \mathrm{~s}^{-1}$. Dispersions of GNP in epoxy resin are stable indefinitely whereas dispersions of GNP 
in acetone separate after a few hours indicating epoxy may have suitable Hildebrand and Hansen solubility parameters for good dispersion.

\section{Method}

GNP was purchased from XG sciences and was Grade M25. It is claimed by the manufacturer that the lateral dimensions of the GNP are roughly $25 \mu \mathrm{m}$ and the thickness is 6-8 $\mathrm{nm}$. The epoxy was purchased from Huntsman consisted of a resin (araldite 564) and a curing agent (aradur 2954).

$0.1 \mathrm{wt} \%$ of GNP was added to $140 \mathrm{~g}$ of resin. The modified resin was then shear mixed for two different lengths of time ( 1 and $2 \mathrm{~h}$ ) and five different speeds (1000 to $5000 \mathrm{rpm}$ ). In total therefore ten samples were made corresponding to the crosses in Table 1. The resin was reweighed and curing agent was added in the ratio $100 \mathrm{~g}$ resin to $35 \mathrm{~g}$ curing agent and stirred at $1000 \mathrm{rpm}$ for $3 \mathrm{~min}$. The mixture was poured into silicon tensile shaped moulds and cured in a Hereus Thermoscientific Oven for $2 \mathrm{~h}$ at $80{ }^{\circ} \mathrm{C}$ followed by $8 \mathrm{~h}$ at $140{ }^{\circ} \mathrm{C}$. In addition, a control sample made from pure epoxy resin was made. Tensile tests were conducted as per ASTM D634 with seven specimens tested per sample. Optical microscopy slides were prepared by drop casting of the mixture on to a glass slide. One extra optical microscopy slide with GNP stirred into epoxy with no shear mixing was also made.

\section{Characterisation}

SEM, FTIR and Raman Spectroscopy were used to characterise the GNP as supplied. Figure 1 shows an SEM image of the GNP. It is difficult to distinguish individual stacks of GNP and that the lateral dimensions appear quite varied to begin with. Figure 2 is the FTIR spectrum which shows no characteristic peaks apart from those at 2350 and $665 \mathrm{~cm}^{-1}$ which can be attributed to atmospheric carbon dioxide. Therefore, the surface is unfunctionalised. From the Raman spectrum in Fig. 3 the intensity ratio between D-band and G-band occur at the characteristic wavenumbers for graphite. The ratio of the intensity of the $\mathrm{D}$ peak to the intensity of the $\mathrm{G}$ peak (ID/IG) is 0.517 for pure GNP. This ratio would concur with details from the supplier that the number of layers of graphene in GNP is 6-8 nm thick i.e. 17-24 layers. Graphene is by definition one layer of graphite however graphene nanoplatelets can have up to 100 layers.

\section{Results and Discussion}

Several observations can be made from the bar charts of strength and Young' modulus. In general, the addition of GNP doesn't improve but rather decreases the tensile strength of the

Table 1 Ten samples were made in the experiment and are marked with an $\mathrm{X}$

\begin{tabular}{llllll}
\hline Time & \multicolumn{2}{l}{ Speed of shear mixer } & & \\
\cline { 2 - 6 } & $1000 \mathrm{rpm}$ & $2000 \mathrm{rpm}$ & $3000 \mathrm{rpm}$ & $4000 \mathrm{rpm}$ & $5000 \mathrm{rpm}$ \\
\hline $1 \mathrm{~h}$ & $\mathrm{X}$ & $\mathrm{X}$ & $\mathrm{X}$ & $\mathrm{X}$ & $\mathrm{X}$ \\
$2 \mathrm{~h}$ & $\mathrm{X}$ & $\mathrm{X}$ & $\mathrm{X}$ & $\mathrm{X}$ & $\mathrm{X}$ \\
\hline
\end{tabular}




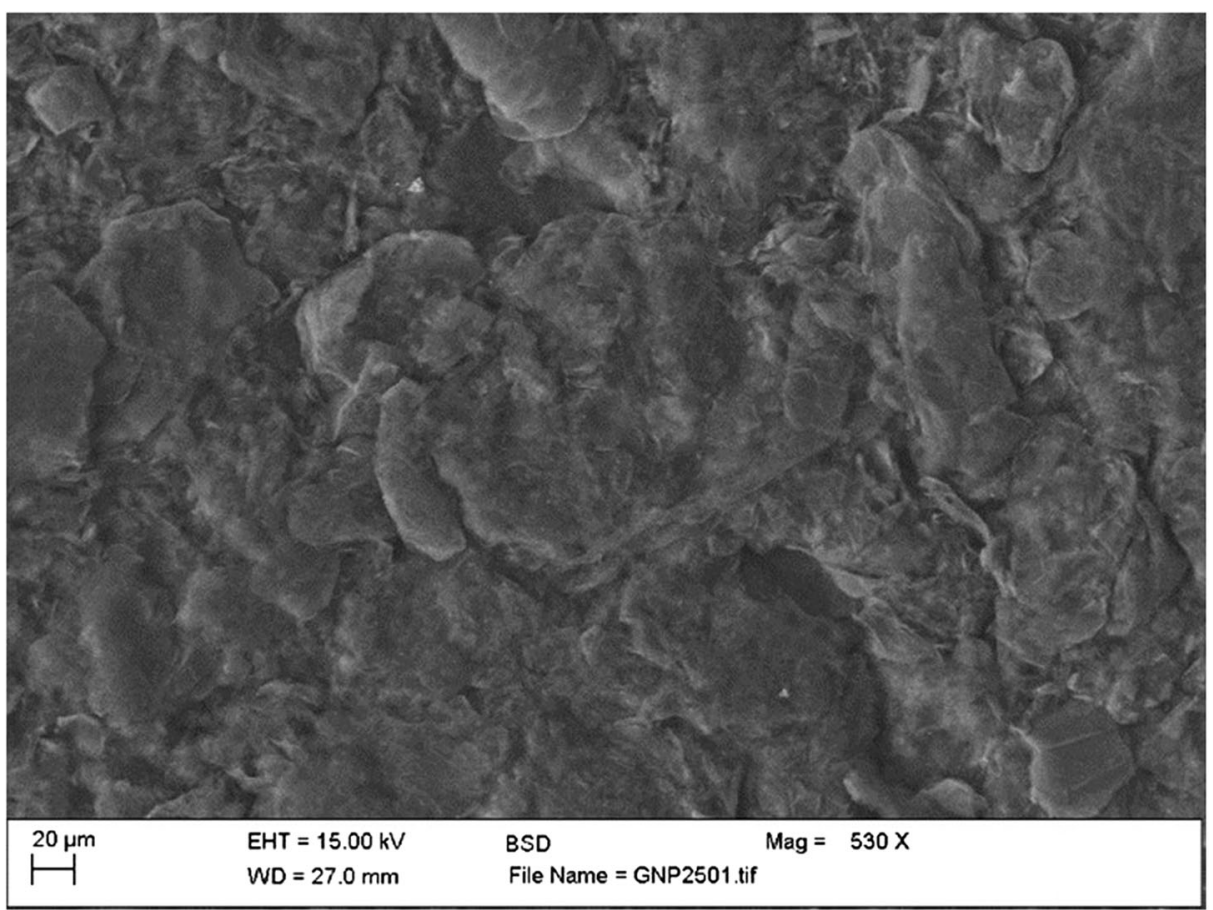

Fig. 1 SEM Image of GNP agglomerates as supplied by XG Sciences

epoxy (see Fig. 4). Secondly there appears to be no trend between the tensile strength and the speed and time of shear mixing. The tensile strength is not linearly decreasing with speed or

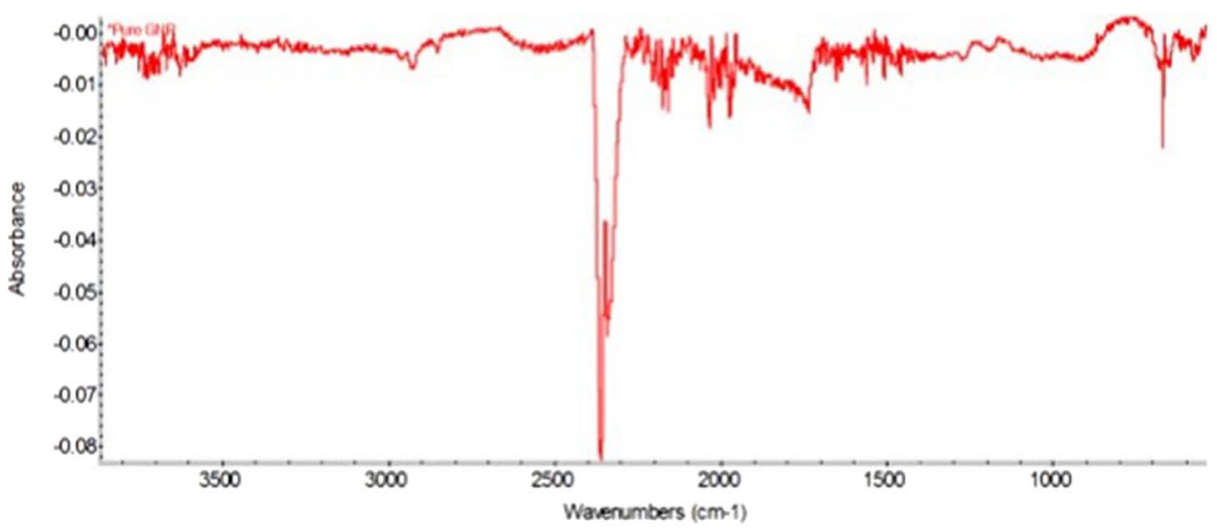

\begin{tabular}{|c|c|}
\hline Approximate Band Position $\left.\mathbf{( c m}^{-1}\right)$ & Functional Groups \\
\hline$\sim 2350$ & atmospheric carbon dioxide \\
\hline$\sim 665$ & atmospheric carbon dioxide \\
\hline
\end{tabular}

Fig. 2 FTIR Spectrum of GNP. The peaks correspond to atmospheric carbon dioxide and so the surface of the GNP is unfunctionalised 


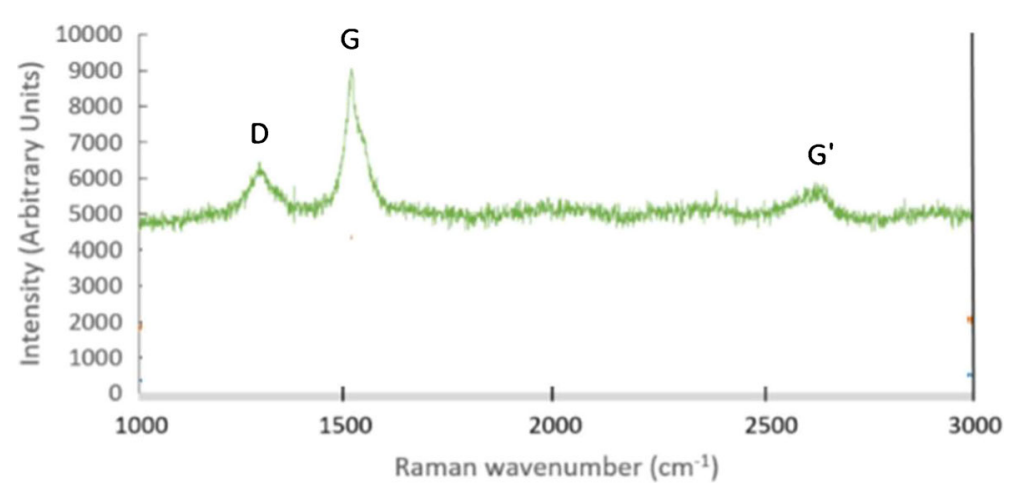

Fig. 3 Raman Spectrum of GNP. The ratio of the intensity of the D band to the intensity of the G band (ID/IG) is 0.517 which concurs with details from the manufacturer that the GNP are between 6 and $8 \mathrm{~nm}$ thick

time but its variation appears to be random. (see Fig. 5). However, there were few improvements. The $3000 \mathrm{rpm} 2 \mathrm{~h}$ sample achieved the highest Young's Modulus averaging 3.02 MPa $(\approx 14 \%$ increase) without reducing the tensile strength and with a small scatter. The highest strength was obtained by the $5000 \mathrm{rpm} 1 \mathrm{~h}$ sample; at these mixing conditions the average size of agglomerate was the smallest, at $20.3 \mu \mathrm{m}$, see Table 1 . The modulus was maintained in this sample. Apart from the $3000 \mathrm{rpm} 2 \mathrm{~h}$ sample (7 tests were performed) however the Young's Modulus remains similar to the neat epoxy value.

\subsection{The Effect of Shear Mixing on the Agglomerate Size}

An important observation is that shear mixing reduces the size of the agglomerates. Comparing Fig. 6f) (no shear mixing) with the Fig. 6a-e we can see that the agglomerates in Fig. 6f) are much bigger than in all the other optical microscope images. It appears that changing the speed and time of shear mixing has an impact on the size of agglomerates. At $3000 \mathrm{rpm}$ and $2 \mathrm{~h}$ of mixing the average size of agglomerate was $26.3 \mu \mathrm{m}$, a $30 \%$ reduction when compared to that of $1000 \mathrm{rpm}$ and $1 \mathrm{~h}$ duration. When Fig. 6a-e are compared to each other, there is little difference between them. By eye it appears that shear mixing for $2 \mathrm{~h}$ does not produce smaller agglomerates than shear mixing for $1 \mathrm{~h}$ and shear mixing at $5000 \mathrm{rpm}$ does not produce smaller agglomerates than mixing at $1000 \mathrm{rpm}$. However, careful measurements demonstrate that the average size of agglomerate at $5000 \mathrm{rpm}$ is $20.3 \mu \mathrm{m}$, with the biggest agglomerate of $73 \mu \mathrm{m}$, while the smallest was $4 \mu \mathrm{m}$, big improvement when compared to those achieved at lower speeds, Table 2. An extra sample was made by shear mixing at a much higher speed of

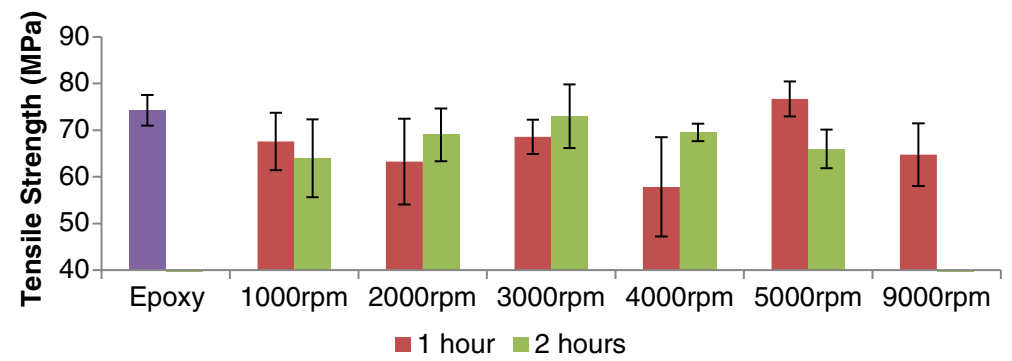

Fig. 4 Tensile Strength of $0.1 \mathrm{wt} \%$ GNP modified epoxy 


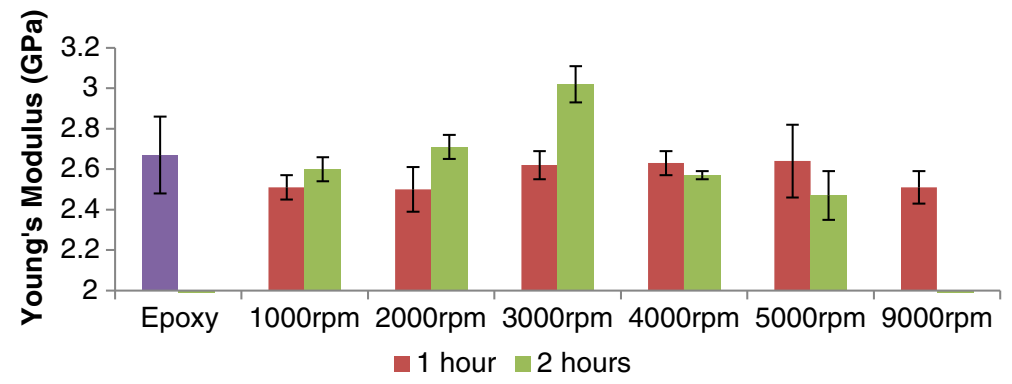

Fig. 5 Young's Modulus of 0.1 wt\% GNP modified epoxy
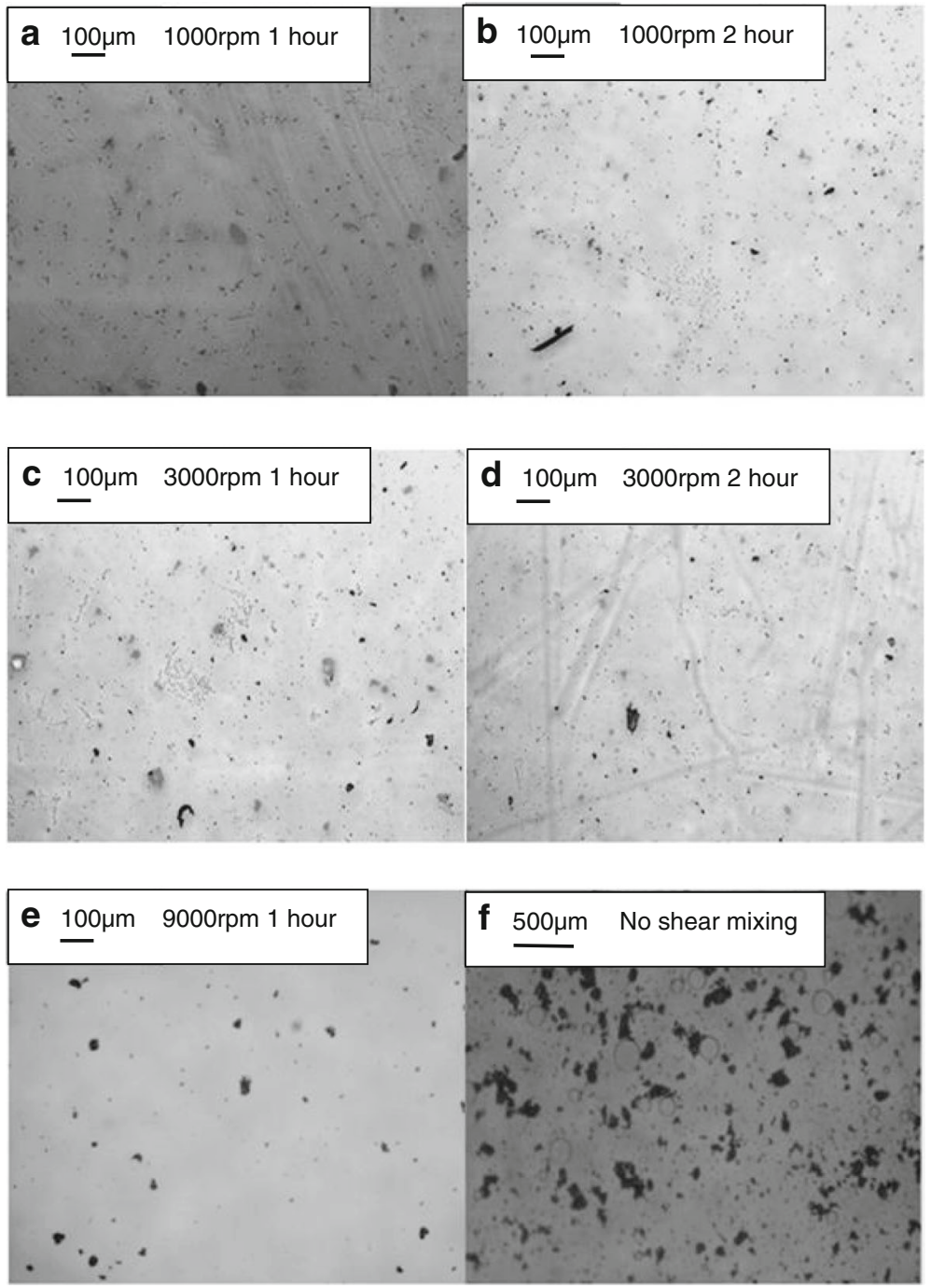

Fig. 6 Optical Microscopy images of samples shear mixed at the following speeds and times a) $1000 \mathrm{rpm} 1 \mathrm{~h} \mathrm{~b}$ ) $1000 \mathrm{rpm} 2 \mathrm{~h} \mathrm{c)} 3000 \mathrm{rpm} 1 \mathrm{~h} \mathrm{~d}) 3000 \mathrm{rpm} 2 \mathrm{~h}$ e) $9000 \mathrm{rpm} 1 \mathrm{~h}$ f) no shear mixing 
$9000 \mathrm{rpm}$ as this should have made an obvious difference. Having examined the optical microscope image of this sample by eye the agglomerates again appear no smaller than any of the other shear mixed samples, the average size was comparable to other mixing conditions of $25.5 \mu \mathrm{m}$, but the size of the biggest agglomerate dropped down to $56 \mathrm{~mm}$ with the smallest one unchanged at $4 \mu \mathrm{m}$. The sizes of the agglomerates for selected images were measured using the microscopy software across five different optical micrographs. The results are recorded in Table 2 suggesting shear mixing at $5000 \mathrm{rpm}$ for $1 \mathrm{~h}$ is the optimal one.

Examining the data of Table 2 it can be seen that the average size of agglomerates decrease with increasing speed and time, although there are few anomalies. For instance, one would expect higher speeds such as the $9000 \mathrm{rpm} 1 \mathrm{~h}$ sample to have smaller average agglomerates than the $5000 \mathrm{rpm} 1 \mathrm{~h}$ sample, which is not exactly the case. The data were collected from one microscope image per sample and from observation across the whole microscope slide there was a large variation in agglomerate size in each sample; further measurements and analysis may be needed to verify these findings before any concluding remarks are made.

Perhaps some re-agglomeration could occurr during curing that could explain some of the observations above. In order to test this hypothesis optical micrographs were monitored during the curing process. The results are shown in Fig. 7. There is no change before and after curing so the micrographs are stable and no re-agglomeration occurred during the curing process.

It can be said though the shear mixing is capable of breaking down primary agglomerates of GNP but only down to a certain size. In addition, it is not effective at controlling the size distribution of the GNP as there is some spread in the size of the agglomerates.

\subsection{The Effect of GNP on Tensile Strength}

One point to discuss is why the tensile strength of the epoxy decreases when the GNP is added to it. It appears as though the GNPs are acting as defects rather than strengthening the epoxy. This could be because the volume fraction of the GNP is so low that by the rule of mixtures it produces a decrease in strength. However, this can be discounted because further work has shown that increasing the loading fraction of GNP produces a greater reduction in strength. Samples were made with $0.1,0.5,1,2$ and $5 \mathrm{wt} \%$ of GNP in epoxy and shear mixed at $5000 \mathrm{rpm}$ for $1 \mathrm{~h}$ (since this resulted to the smallest average size of agglomerate). The tensile strength is reduced linearly with the loading weight of the GNP (See Fig. 8).

Another reason why the strength decreases could be because the sizes of the GNP agglomerates are too large and act as stress raisers which cause premature failure. There were a few agglomerates which were bigger than $100 \mu \mathrm{m}$. In Fig. 9 is a close up of agglomerate from the $1000 \mathrm{rpm} 1 \mathrm{~h}$ optical microscope slide. The agglomerate measures $169 \mu \mathrm{m}$ and is surrounded by smaller agglomerates. It has rough edges and sharp corners which could be big enough to act as stress raisers. It only requires one stress raiser to create a catastrophic crack

Table 2 Measurements of agglomerate sizes across five different optical micrographs

\begin{tabular}{lllll}
\hline & $\begin{array}{l}1000 \mathrm{rpm} \\
1 \mathrm{~h}\end{array}$ & $\begin{array}{l}5000 \mathrm{rpm} \\
1 \mathrm{~h}\end{array}$ & $\begin{array}{l}9000 \mathrm{rpm} \\
1 \mathrm{~h}\end{array}$ & $\begin{array}{l}3000 \mathrm{rpm} \\
2 \mathrm{~h}\end{array}$ \\
\hline Average size of agglomerate $(\mu \mathrm{m})$ & 37.5 & 20.3 & 25.5 & 26.3 \\
Biggest agglomerate $(\mu \mathrm{m})$ & 169 & 73 & 56 & 123 \\
Smallest agglomerate $(\mu \mathrm{m})$ & 7 & 4 & 4 & 4 \\
\hline
\end{tabular}



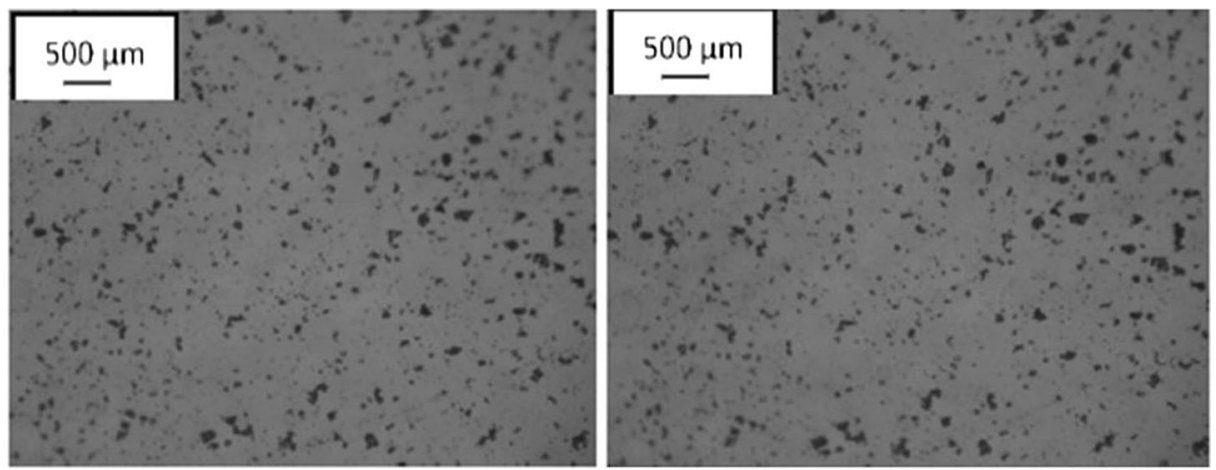

Fig. 7 Comparison of Microstructure before curing (left) and after curing (right). There was no difference between the micrographs so no re agglomeration occurred during curing

which leads to failure of the sample. However, there are many other studies using functionalised graphene where agglomerates are similar sizes to the agglomerates in this study and yet there are improvements in tensile strength [3-6]. Therefore, agglomerate size cannot be the sole reason for the reduction in strength there must be something else at play.

The most likely explanation for the reduction in properties is the lack of an optimised interface between the GNP and the epoxy. There was no functionalisation on the surface of the GNP as shown by FTIR so the bond with the epoxy could have been weak and the wetting of the surface could have been poor. Most research has shown there is improvement in the tensile properties when the surface of graphene has been modified with oxygen atoms [4, 7-11]. Therefore, functionalisation of the surface of graphene appears to be the critical factor for improvement of mechanical properties.

An extra experiment was conducted using acetone as a solvent to see if it assisted the dispersion. GNP was mixed with equal amounts of acetone and epoxy for $5000 \mathrm{rpm}$ and $1 \mathrm{~h}$. The acetone was then evaporated off by heating the mixture to a constant mass. The results are also shown in Fig. 8. As can be see then acetone samples are very similar to the epoxy sample so from the tensile strength point of view the acetone does not have an effect.

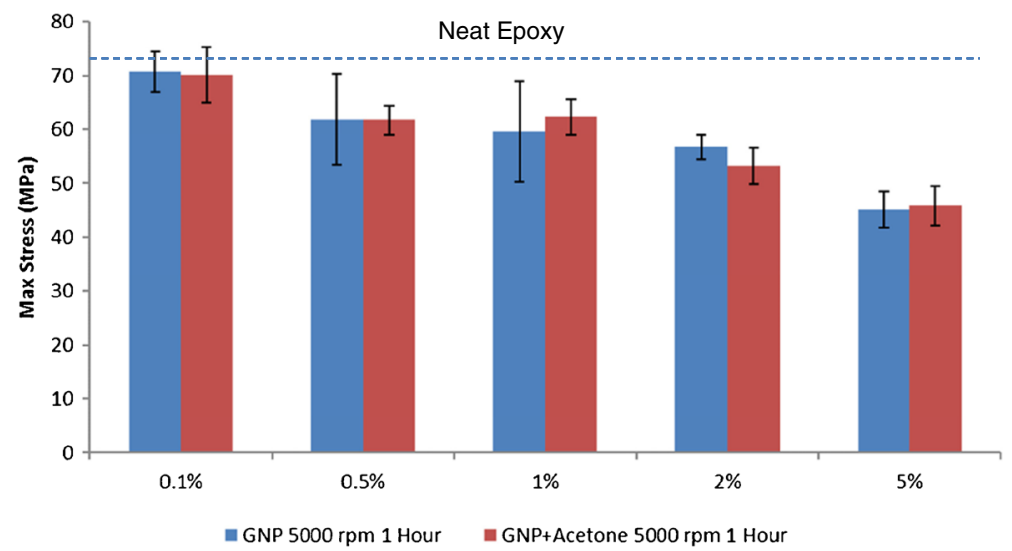

Fig. 8 Variation of tensile strengths with loading wt\% of GNP in epoxy with and without acetone mixed at $5000 \mathrm{rpm}$ for $1 \mathrm{~h}$ 
Fig. 9 Optical microscope image of GNP agglomerate taken from the $1000 \mathrm{rpm} 1 \mathrm{~h}$ sample

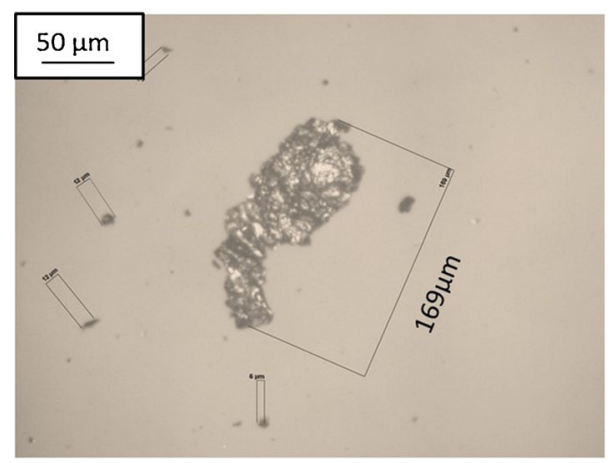

\subsection{The Effect of GNP on Young's Modulus}

The speed and time of shear mixing has an impact on the Young's modulus of the epoxy. There is an increase in Young's Modulus at $3000 \mathrm{rpm} 2 \mathrm{~h}$ up to $3.02 \mathrm{GPa}$ compared to 2.62 GPa for epoxy. The increasing trend does not continue at 5000 and $9000 \mathrm{rpm}$, Fig. 5, therefore appears as if it is within experimental fluctuations. In addition, when the weight percentage of GNP was increased (see Fig. 10) there was no significant increase in the Young's Modulus. The lack of effect would be consistent with the finding that there is no bond between the GNP and the epoxy and therefore does not contribute to the stiffness of the composite.

The results using acetone as a solvent are shown in Fig. 10. The results show that adding acetone improved the Young's Modulus of the epoxy up to $3 \mathrm{GPa}$ at $5 \mathrm{wt} \%$. However, it is not clear whether it was the acetone which caused the improvement or because the GNP was better dispersed. Therefore, a control was made where acetone was shear mixed in epoxy at $5000 \mathrm{rpm}$ for $1 \mathrm{~h}$ without GNP. The acetone was then evaporated and the epoxy was cured in the normal way. An average of $2.68 \mathrm{MPa}$ was recorded for the Young's modulus which is

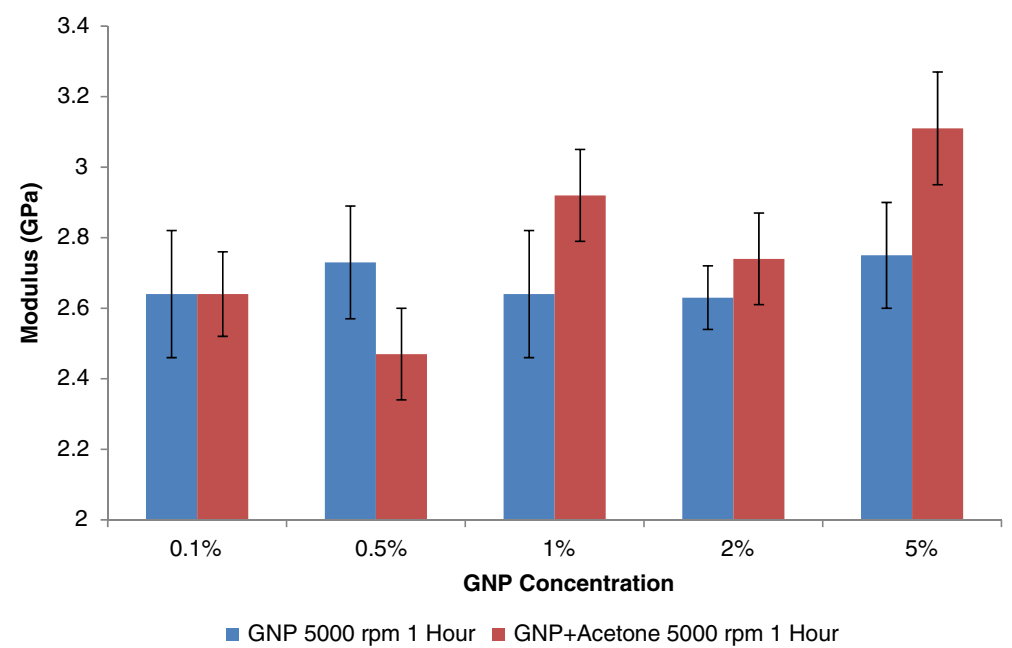

Fig. 10 Variation of Young's Modulus with loading wt\% of GNP with and without acetone as a solvent mixed at $5000 \mathrm{rpm}$ for $1 \mathrm{~h}$ 


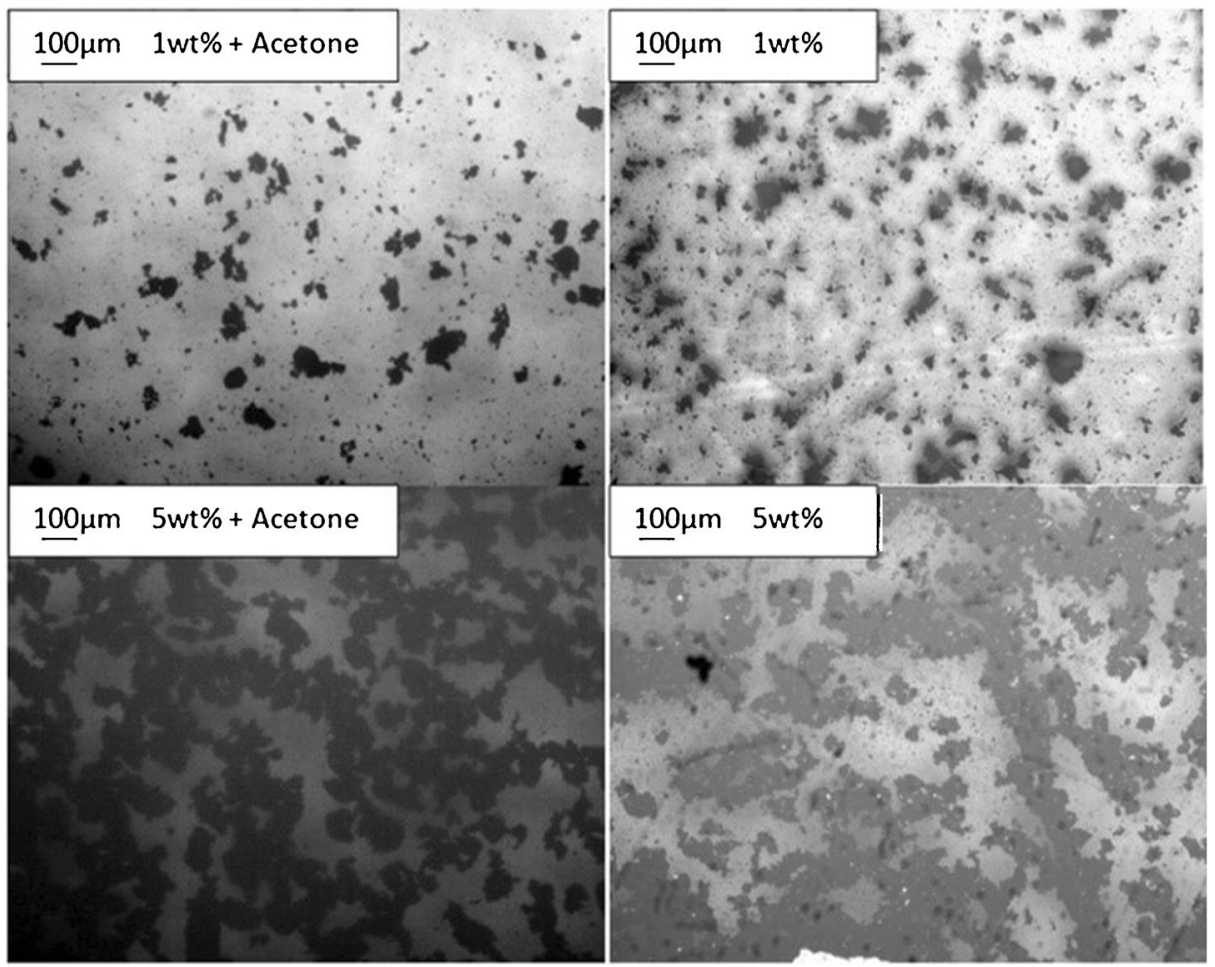

Fig. 11 Optical micrographs from GNP mixed with and without acetone at $5000 \mathrm{rpm}$ for $1 \mathrm{~h}$

pretty much the same as pure epoxy which suggests that it is not the acetone which is responsible for the improvement but the effect of the acetone on the dispersion of the GNP. If the dispersion was better, then this should be visible on the optical microscopy slides for the samples shown in Fig. 11. Having examined the difference between them there does not appear to be a better dispersion in the acetone samples than without. Further work is required to understand why there is an improvement in modulus with the addition of acetone. More optical microscope images from different locations could help in this respect.

\section{Concluding Remarks}

This study has shown that shear mixing can reduce the size of GNP agglomerates in epoxy. Shear mixing produces a broad range of sizes ranging from $\sim 100 \mu \mathrm{m}$ to less than $10 \mu \mathrm{m}$. The $3000 \mathrm{rpm} 2 \mathrm{~h}$ sample achieved the highest Young's Modulus averaging $3.02 \mathrm{GPa}(\approx 14 \%$ increase) without reducing the tensile strength and with a standard deviation of $0.09 \mathrm{GPa}$. The highest strength was obtained by the $5000 \mathrm{rpm} 1 \mathrm{~h}$ sample which was $76.68 \mathrm{MPa}$; at these mixing conditions the average size of agglomerate was the smallest, at $20.3 \mu \mathrm{m}$. In general, the addition of GNP to epoxy reduces the strength of the epoxy most probably because of a lack of functionalisation and a strong bond between them. The most important factor for the improvement of mechanical properties appears to be the functionalization of the GNP and of course the size of the GNP agglomerates does have also an influence. Another important conclusion is that no re-agglomeration occurs during curing. Acetone can be used as a low cost solvent (that 
easily evaporates and removed) to improve the Young's Modulus of GNP/epoxy composites, but further work is needed to understand why.

Open Access This article is distributed under the terms of the Creative Commons Attribution 4.0 International License (http://creativecommons.org/licenses/by/4.0/), which permits unrestricted use, distribution, and reproduction in any medium, provided you give appropriate credit to the original author(s) and the source, provide a link to the Creative Commons license, and indicate if changes were made.

\section{References}

1. Paton, K.R., et al.: Scalable production of large quantities of defect-free few-layer graphene by shear exfoliation in liquids. Nat. Mater. 13(6), 624-630 (2014)

2. Hernandez, Y., et al.: Measurement of multicomponent solubility parameters for graphene facilitates solvent discovery. Langmuir 26(5), 3208-3213 (2010)

3. Tang, L.-C., et al.: The effect of graphene dispersion on the mechanical properties of graphene/epoxy composites. Carbon 60, 16-27 (2013)

4. Wan, Y.-J., et al.: Grafting of epoxy chains onto graphene oxide for epoxy composites with improved mechanical and thermal properties. Carbon 69, 467-480 (2014)

5. Wan, Y.-J., et al.: Mechanical properties of epoxy composites filled with silane-functionalized graphene oxide. Compos. Part A Appl. Sci. Manuf. 64, 79-89 (2014)

6. Yasmin, A., Daniel, I.M.: Mechanical and thermal properties of graphite platelet/epoxy composites. Polymer 45(24), 8211-8219 (2004)

7. Park, S., et al.: Graphene oxide papers modified by divalent ions - enhancing mechanical properties via chemical cross-linking. ACS Nano 2(3), 572-578 (2008)

8. Rafiee, M.A., et al.: Enhanced mechanical properties of nanocomposites at low graphene content. ACS Nano 3(12), 3884-3890 (2009)

9. Chen, L., et al.: Enhanced epoxy/silica composites mechanical properties by introducing graphene oxide to the interface. ACS Appl. Mater. Interfaces 4(8), 4398-4404 (2012)

10. Naebe, M., et al.: Mechanical property and structure of covalent functionalised graphene/epoxy nanocomposites. Sci. Rep. 4, 4375 (2014)

11. Wang, X., et al.: Covalent functionalization of graphene with organosilane and its use as a reinforcement in epoxy composites. Compos. Sci. Technol. 72(6), 737-743 (2012) 